\title{
Research by Online Education for a New Era on the Dependence of Vocational Students on Mobile Phones and Their Loneliness
}

\author{
Weiwei Zhou ${ }^{1,2}$ Renfang Han ${ }^{1^{*}}$ Faming Pan $^{1}$ \\ 1. School of Public Health of Anhui Medical University, Hefei, Anhui, 230032, China \\ 2. Department of Medicine of Huaibei Vocational \& Technical College, Huaibei, Anhui, 235000, China
}

\section{ARTICLE INFO}

Article history

Received: 14 September 2021

Revised: 25 September 2021

Accepted: 15 October 2021

Published Online: 30 October 2021

\section{Keywords:}

Online education

Vocational students

Dependence on mobile phones

Loneliness

\section{Introduction}

Most of vocational students didn't perform well in the previous study, so they are immature in their body and mind. After access to fresh things, these students may be highly desirable for exploration, much curious and dependent on fresh things over time, sort out the persons and things around them gradually, and trigger strong loneliness eventually, making students lose the desire to communicate and exchange with other persons in study and lives. With a view to address such dependence of students on mobile phones and their loneliness in vocational education work, the online education is described in the paper, and the dependence of vocational students on mobile phones as well as their loneliness are solved through online education.

\begin{abstract}
More and more problems have been arisen from higher social development level and more and more terminal devices, especially addictive devices have been exposed to the education field during the constant development of cutting-edge techniques, thus making students more and more dependent on mobile phones and other terminal devices. In this process, students tend to more depend on mobile phones, which will make students sort out the exchange and communication with other persons by taking mobile phones as the core and be lonely. It is very important for the current vocational education to research the dependence of students on mobile phones and their loneliness, and break the deadlock. Therefore, in this paper, the online education is researched, and the dependence of vocational students on mobile phones as well as their loneliness are solved based on online education.
\end{abstract}

\section{Concept and Advantages of Online Education}

\subsection{Concept of Online Education}

Online education is a novel mean of education derived from the rapid development of information technology and multimedia technology in the new era and traditional teaching class is transformed to online teaching platform to enable students to access to knowledge and question answers based on a more open and freer teaching platform. In the new era, the indoctrination of more concepts and ideas makes students more and more curious about new things; due to immature body and mind, there are a lot of problems for students to identify emerging things and new concepts, impacting the judgement of future development of students. Through online education,

*Corresponding Author:

Renfang Han,

School of Public Health of Anhui Medical University, Hefei, Anhui, 230032, China;

Email:peca@163.com 
students can learn more about current new technical theories, cognize surrounding emerging things and new concepts correctly, grasp right outlook on life, world outlook and values, solve the problems arising from their study, enhance utilization of emerging things and achieve all-round progress with students as the core ${ }^{[1]}$.

\subsection{Advantages of Online Education}

Firstly, online education breaks the traditional concept of education. The education concept held by online education is novel and contains a lot of teaching methods as well as design methods different from traditional education. The backward concepts and unscientific actual methods in traditional teaching incur a lot of problems in actual teaching. The preliminary research purpose is to address the problems in the traditional teaching. The teaching concepts and teaching means are very novel and complied with the student requirements and student characteristics in the new era. For instance, the introduction of new teaching platforms and new teaching concepts during education enables teachers to grasp new teaching techniques, spontaneously take up research on online education, carry out education based on actual characteristics of students and achieve targeted teaching ${ }^{[2]}$.

Secondly, online education carries out teaching embarked on specific characters of students. As the specific characters of students are fully embodied in online education, teachers can fully understand the characters of all students, build more targeted teaching means as well as communication means, and completely activate personal interests as well as personal merits of students. In particular, in the new century, online education stresses to respect the dominant position of students and play the dominant role of students. Therefore, the work platforms and teaching means based on online education enable students to fully exhibit themselves in a freer and more open environment and select courses embarked on their actual requirements ${ }^{[3]}$.

Online education is an inevitable requirement of education and teaching reform in the new century and an inevitable development trend of future education, so education and teaching work shall be changed toward online education mode, and teachers shall constantly update their teaching mode and concept and enhance the storage of all knowledge as well as skills relating online education through self-learning.

\section{Dependence of Vocational Students on Mobile Phones and Loneliness}

Mobile phone dependence, also known as mobile phone syndrome, refers to that individuals are out of control in use of mobile phones, obviously hurt in personal physiology, psychology and social functions and addicted to mobile phones for long. The dependence on mobile phones isn't a dependence on the devices but the contents in mobile phones such as network games, messages, shooting and other functions. Such a dependence will make students absent in study and even impact their psychological health development. Therefore, mobile phone dependence is not behavioral addiction in essence, and is a universal phenomenon in the current vocational colleges in China. Many users who forget to carry mobile phones will feel uncomfortable and even intolerable ${ }^{[4]}$, and they have to keep mobile phones around them. It is found from the survey that the vocational students who cannot receive messages for long may even have phonism. With the constant sci-tech development, mobile phones are a kind of tools for information exchange in essence and used by more and more persons. Why the students are dependent on mobile phones is that students are deficient in characters such as introversion, solitariness and social withdrawal or are nervous and stressed in work.

In special cases, the excessive utilization of mobile phones will incur certain negative emotional experience as well as psychological changes, and the excessive dependence on mobile phones will dissimilate the mobile phone users, thus objectifying subjects. Among the vocational students, as girls are richer in emotional experience than boys, girls will be richer in emotional activities than boys. It is discovered from the survey on vocational students that girls bear more campus stress as well as negative events and feel lonelier than boys. Though this phenomenon cannot prove that gender has direct relations with mobile phone dependence and loneliness, it can fully prove that the excessive use of mobile phones will incur addiction, further form dependence and eventually evolve to loneliness ${ }^{[5]}$.

\section{Causes of Mobile Phone Dependence and Loneliness of Vocational Students}

Firstly, because they didn't perform well in the previous study, the vocational students may be diffident in the colleges. These students will take mobile phones as the only channel to communicate with and learn from the external world during use of mobile phones, so they are more dependent on mobile phones than other students. In addition, during use of mobile phones, the students will be gradually attracted by the fresh things and phenomenon in mobile phones, gradually sort out the persons and things around, stay in the worldlet formed by interconnection of students with mobile phones and pay less and less 
attention to external things.

Secondly, loneliness is produced by illusion. As a mobile terminal, a mobile phone will transmit false information. Some information is evolved based on reality but may be exaggerated during communication. It is certainly difficult for these students to identify the information and make accurate judgement on the trueness of information, so they may be misled by these information and have wrong feelings. In particular, certain network we-media agencies get profit by spreading the illusory and untrue information. Therefore, most of these information are transmitted to cater for the youngers. The students may be attracted by these information and more dependent on mobile phones. Moreover, the students may be immersed in these untrue and illusory information, and may have psychological gap and feel lonely and frustrated after exposure to the real life ${ }^{[6]}$.

\section{Solution of Mobile Phone Dependence and Loneliness of Vocational Students Based on Online Education}

\subsection{Strengthen Basic Research}

Before conducting online education, teachers shall learn and grasp the design requirements reflected by the existing students in routine teaching; in particular, the dissatisfaction and problems of the students to the teaching in traditional classes need to be solved by online education. Therefore, teachers shall enhance the understanding of students; in particular, the odd students are unable to express their dissatisfaction or problems to the teaching, so the teachers shall observe these students and collect the questions of the students in study. Then teachers shall design the work contents and teaching plans of online education combined with the differences among students and enable students to be attracted by teaching contents and activities designed by teachers in this way.

\subsection{Enhance the Optimal Combination of Teaching Elements}

When the causes of mobile dependence and loneliness of students are analyzed during previous study by vocational students, it is discovered that some students are not very interested in the study or the teaching contents, making them shift their interests to other things. With a view to enable to alleviate the mobile phone dependence and resulted loneliness of students, all elements of teaching shall be effectively integrated. The main purpose of online education, especially the new education concepts and teaching modes proposed based on the reform of teaching in the new era is to enable students to fully express themselves during study and improve their interests in study, so teachers shall combine the teaching elements embarked on the study interests and characters of students to activate the interests and desires of students in study so that the students can be much curious in the teaching contents. To this end, teachers shall really understand students during teaching and optimally combine the teaching elements and activity elements they grasp to enable students to be attracted by the teaching contents during study and actively participate in the links of teaching ${ }^{[7]}$.

\subsection{Build a Professional Teaching Platform}

Online education is the main development direction of future teaching and the main development trend of current education. With a view to enable online education to give play to their advantages, a professional teaching platform shall be built to enable students to full express themselves, make a speech during online study, conduct efficient communication and exchange with teachers based on the online education platform, get out of the worldlet and really fit in colleges. The vocational colleges shall build a professional online education platform based on IT development trend and development status in education work and constantly consummate the module of the education platform. Teachers shall explain and distinguish the importance of mobile phones as well as other electronic devices and existing study/work for students, enable students to cognize that they can relax and entertain through mobile phones and other mobile terminal electronic devices in spare time, study is the main task at present ${ }^{[8]}$, the significance of friendship and cooperation with classmates during study to future development of students and what the current focus is.

\section{Conclusions}

To be concluded, students are facing more and more lures in study and life with social progress and rapid development in the new era. If students are unable to exactly identify these external influencing elements, they may be much impacted during study. Mobile phones are the main means to influence the current study. Most of the students are very curious and eager in emerging things, but excessive curiosity or exploration may produce dependence and even loneliness. Therefore, vocational colleges shall alleviate the dependence of students on mobile phones through online education and enable students shift their focus onto study. 


\section{References}

[1] Liu Hong, Wang Hongli. Dependence of Students on Mobile Phones and Their Loneliness [J]. Chinese Mental Health Journal, 2012, 26(1):66-69.

[2] Sun Jiangwei, Li Lin, Lin Chao, et al. Relationship of Mobile Phone Dependence Syndrome with Loneliness of Students [J]. Chinese Journal of Public Health, 2014, 30(9):1147-1150.

[3] Wei Yaoyang. Research on Relationship of Mobile Phone Dependence with Loneliness of Students [J]. Journal of Liaocheng University: Natural Science Edition, 2013.

[4] Wei Yaoyang. Research on Relationship of Mobile Phone Dependence with Loneliness of Students [J]. Journal of Liaocheng University (Natural Science Edition), 2013(01):83-85.
[5] Li Jing, Yan Guowei, Zhang Jingping. Relationship of Mobile Phone Dependence with Loneliness of Medical Students: Mediating Role of Coping Style [J]. China Journal of Health Psychology, 2016, 24(012):1828-1831.

[6] Liu Zhiqiang. Influence of Loneliness on Dependence of Vocational Students on Smart Phones [J]. Sichuan Mental Health, 2014, 27(001):16-18.

[7] Liu Yan, Zhou Shaobin. Relationship among Self-esteem, Social Problem Solution, Loneliness and Mobile Phone Dependence of Fresh Vocational Students [J]. China Journal of Health Psychology, 2019, 027(005):777-780.

[8] Tu Wei. Research on Social Support, Loneliness and Mobile Phone Dependence of Students [J]. The Guide of Science \& Education (Midmonth Journal), 2016. 